WSRC-RP-92-187

DE92 015885

\title{
MEASUREMENTS AND PRELIMINARY INTERPRETATION OF K- REACTOR FOUNDATION RESPONSE TO MAN-MADE SEISMIC EXCITATION (U)
}

by

R. C. Lee and D. E. Stephenson

Environmental Sciences Section

Westinghouse Savannah River Company

Savannah River Technology Center

This is an external document to OSTI

\section{DISCLAIMER}

\begin{abstract}
This report was prepared as an account of work sponsored by an agency of the United States Government. Neither the United States Gnvernment nor any agency thereof, nor any of their employees, makes any warranty, express or implied, or assumes any legal liability or responsibility for the accuracy, completeness, or usefulness of any information, apparatus, product, or process disclosed, or represents that its use would not infringe privately owned rights. Reference herein to any specific commercial product, process, or service by trade name, trademark, manufacturer, or otherwise does not necessarily constitute or imply its endorsement, recommendation, or favoring by the United States Government or any agency thereof. The views and opinions of authors expressed herein do not necessarily state or reflect those of the United States Government or any agency thereof.
\end{abstract}

The information contained in this paper was developed during the course of work done under Contract No. DE-AC09-89SR18035 with the U.S. Department of Energy. By acceptance of this paper the publisher and/or recipient acknowledges the U.S. Government's right to retain a nonexclusive, royalty-free license in and to any copyright covering this paper, along with the right to reproduce and to authorize others to reproduce all or part of the copyrighted paper. 
Derivative Classifier Brmoore-Lhenes

D.B. Moore-Shedrow, Section Manager

\section{Measurements and Preliminary Interpretation of K-Reactor Foundation Response to Man-Made Seismic Excitation (U)}

R.C. Lee and D.E. Stephenson

Environmental Sciences Section

Westinghouse Savannah River Company

Savannah River Technology Center

April 10, 1992

Authentication:

D.B. Moore-Shedrow, Manager

Environmental Sciences Section

Savannah River Technology Center

The information contained in this article was developed during the course of work under Contract No.

DE-ACO9-89SR18035 with the U. S. Department of Energy. By acceptance of this paper, the publisher and/or recipient acknowledges the U.S. Govemment's right to retain a nonexclusive, royalty-free license in and to any copyright covering this paper along with the right to reproduce, and to authorize others to reproduce all or part of the copyrighted paper. 


\title{
Measurements and Preliminary Interpretation of K-Reactor Foundation Response to Man-Made Seismic Excitation (U)
}

\author{
R. C. Lee and D. E. Stephenson \\ Westinghouse Savannah River Company \\ Savannah River Site \\ Aiken, SC 29808
}

\begin{abstract}
In suppart of the Savannah River Technology Center (SRTC) effort to develop K-Reactor seismic design basis ground motions, SRTC monitored local high-explosive tests at a "free-field" site adjacent to K-Reactor and on the - 40 level on the foundation of K-Reactor. The high-explosive tests were part of the SRTC/United States Geological Survey (USGS) regional refraction and attenuation experiment that used deeply buried high explosive charges near New Ellenton, Snelling, and at more distant South Carolina sites. The primary purpose of the Reactor measurements are to compare the relative amplitude and frequency content of ambient noise and shot generated ground motions measured at the $\mathrm{K}$-Reactor foundation level and in the "free-field" so that foundation effects to ground motions can be documented and possibly incorporated in the facility design basis. Data analysis indicates that one of the five high explosive tests provided sufficient excitations at $\mathrm{K}$-Reactor to produce satisfactory signal-to-noise between about $1 \mathrm{~Hz}$ and $15 \mathrm{~Hz}$. Within this frequency band, Fourier spectral amplitude ratios of motions recorded within the first 10 seconds of first motion show substantial reductions (30-50\%) on shot radial and transverse components for frequencies greater than about 3 to $5 \mathrm{~Hz}$. Approximately $50 \%$ reductions between 10 to $15 \mathrm{~Hz}$ were seen on vertical component ratios, and amplifications of $100 \%$ at $4 \mathrm{~Hz}$ and $5 \mathrm{~Hz}-6 \mathrm{~Hz}$.
\end{abstract}

\section{Introduction}

In April, 1991, at the request of the Savannah River Technical Center (SRTC) Earth Sciences Advisory Committee (ESAC), the SRTC Logether with the United States Geological Survey (USGS) conducted a seismic refraction experiment to estimate regional ground motion attenuation and site amplification effects at the Savannah River Site (SRS). A series of high explosive shots were used as energy sources. In addition to those measurements, the experiment afforded an opportunity for SRTC to measure motions simultaneously on the foundation of K-Reactor and in the near vicinity free-field to observe effects of the reactor foundation to ground motions. This report details that aspect of the attenuation experiment and the preliminary analysis of data recorded at $\mathrm{K}-\mathrm{Reactor}$.

It has long been recognized that large embedded structures have an effect on recorded earthquake motions and there is a significant body of theoretical analyses applied to that estimate. Ground motion predictions for critical structures depend in part on observed earthquake strong motion data collected in comparable geologic environments; instrument platforms range from sensors placed in the soil or small instrument pads to recordings made on foundations of large structures with deeply embedded foundations. Statistical studies of earthquake strong motion data show that building effects on strong ground motion are statistically significant (Campbell, 1989). Smaller peak ground accelerations and lower short period response are associated with commercial buildings greater than three stories in height, as compared to free-field sites and smaller buildings (longer period motions are greater in the structures). The few recordings available on large embedded structures (a class of structure similar to K-Reactor) indicates that such structures act as a 
low-pass filter because of scattering and/or averaging of the seismic wave field.

Unfortunately, simultaneous and nearby recordings of earthquakes in both the structure and adjacent "freo-field" (herein to mean a ground surface recording sufficiently far from a structure to be free of wave field scattering and ground motion induced resonances from nearby structures, and sufficiently close to anticipate otherwise coherent sig. nals at both locations) are rare in the U.S. and are not available for facilities in the Southeastern United States (SEUS). Thus, foundation motion predictions of critical structures may not account for foundation effects or the predictions depend on uncertain theoretical models of soil and structure interaction.

In lieu of historic recordings of foundation and free-field earthquake strong motions in the eastem U.S., it is possible to record man-made explosions to estimate empirical transfer functions between free-field and foundation. The difficulty with this approach is that local, shallow explosive sources generate predominantly P-wave energy, unlike earthquakes which are rich in $\mathrm{S}$-waves. Such an experiment was developed for the Virgil C. Summer Nuclear Poiver Generating Station in South Carolina. In that experiment, small shallow explosive charges were set at distances of a few hundred meters from instruments recording motions in the reactor and in the iree-field. Experimental transfer functions were used to satisfy a licensing requirement by the Nuclear Regulatory Commission (NRC) to show that a shallow reservoir induced earthquake could not produce high frequency motions on the foundations in excess of design basis predictions (SCE\&G, 1983).

The explosive tests were conducted on the night of April 7, 1991. Using sensitive, high cynamic range sensors and recorders it is possible to compare waveforms, peak motions, and spectral amplitudes recorded inside and outside the $\mathrm{K}$ Reacior. If seismic excitations exceed seismic noise generated inside and outside the structure, it may be possible to measure the foundation influence over a wide frequency band. The purpose of the measurements described in this report were to: (1) measure ambient noise levels at relatively quiet sites within and adjacent to K-Reactor; (2) measure ground motion during the experiment window to determine whether shot motions could be resolved in high noise reactor environments; and (3) if signals are present, determine wide-band empirical transfer functions for $\mathrm{K}$-Reactor foundation.
Kinemetrics and Agbabian Associates were contracted to assist in the programming of the digital event recorders and provide necessary documentation of sensor calibration. This report documents the data collection activities and initial data analysis performed by the seismic group of SRTC/ Environmental Sciences Section (ESS).

\section{Experiment Configuration and Procedures}

The USGS/SRTC ground motion and attenuation experiment is illustrated Figures 1,2 , and 3 . The refraction/wideangle reflection experiment used five high explosive shots set-off in cased holes in Coastal Plain Sediments, or in bedrock (Paleozoic crystalline or Triassic basin fill materials). This $120 \mathrm{~km}$ profile starts from just north of the site near New Ellenton, running across the north-eastern side of the SRS to the southeast towards Charleston (terminating near Walterboro). Vertical and horizontal component ground motion measurements were made approximately every kilometer along the refraction line. This configuration runs against the strike of the Piedmont/Coastal Plain geology to maximize recording of wave propagation effects in those structures, and also provides structural information on an SRS-to-Charleston azimuth for purposes of reducing uncertainty in wave propagation characteristics for future Charleston 1886 "type" earthquakes. The shots were set for Sunday, April 7, at 10:00 pm local time, with the five shot sequence starting at New Ellenton and subsequent shots 2 minutes apart except for Walterboro which was timed one hour later.

Charge sizes ranged from $910 \mathrm{Kg}(2000 \mathrm{lb})$ to $410 \mathrm{Kg}$ (900 lb) of TNT equivalent chemical explosive. The shot-to-KReactor distances were 22, 20, and $38 \mathrm{~km}$ for the New Ellenton, Snelling, and Olar shots (Shots labeled 1, 2, and 3 in Figure 1). Table 1 and Figure 3 contains a summary of the shots and K-Reactor distances.

Criteria for placing Reactor recording instruments were to insure that differences in motions were a result of foundation effects only: (1) a free-field site sufficiently distant from scattered wave field to be free of reactor induced motions and sufficiently distant to have lower noise levels; (2) locate free-field instrument between shot and reactor to reduce scattered wave fisld; (3) sufficiently close to reactor such that wave field from shot is coherent (at lower frequencies) and to insure that material properties of free-field soil column similar to reactor soil column; and (4) recorder loca- 
tion placed at lowest level of K-Reactor foundation ( -40 level) and at a relatively quiet site.

Seismic sensors and recorders were positioned at a freefield site near the Burning/Rubble Pit adjacent to monitoring well KRP 1, approximately 2,000 feet north-northeast of the -40 level (foundation) recorder at the eastern corner of the reactor. Figure 4 shows the recorder locations with respect to the K-Area security fence, building outline, and Receiving Basin. Also shown are the shot azimuths for the New Ellenton and Snelling shots. Horizontal components of both sensor sets were orthogonal and oriented along the building north-south and east-west axes.

\section{K-Reactor Ground Motion Monitoring Systems}

The digital seismic event recorders, were pre-programmed to turn-on and record continuously for the ten-minute period window. A three channel and a six channel Kinemetrics Model SSR-1 digital event recorder were employed for this task. Each recorder monitored signals from a triaxial set of Kinemetrics Model SS-1 Ranger seismometers measuring ground velocity, and in addition, the K-Reactor recorder also monitored three-components of acceleration using a Kinemetrics Model FBA-23 triaxial accelerometer.

The SSR-1 is a self contained, programmable, three to six channel digital event recorder with $16 \mathrm{bit}(96 \mathrm{db})$ resolution that records data in solid state memory. The recorder was programmed to anti-alias filter frequencies greater than 50 $\mathrm{Hz}$ and to record 200 samples/sec on each channel. The trigger mode for the SSR was programmed to do continuous 10 -minute recording starting approximately one minute before the first scheduled shot. Recovery of data from the SSR-1 was via serial port communication to an IBM compatible computer and special communications software provided by the vendor.

The FBA-23 is a force balance triaxial accelerometer having a dynamic range of $120 \mathrm{db}$ and flat frequency response between 0 and $50 \mathrm{~Hz}$. Full scale range was $+/-2.0 \mathrm{~g}$ with a natural frequency of $50 \mathrm{~Hz}$, and damping of $70 \%$ of critical. The SSR-1 system together with the FBA-23 are capable of recording on scale accelerations from $+/-2.0 \mathrm{~g}$ to $+/-$ $0.00006 \mathrm{~g}$, depending on the trigger mode.
The SS-1 Ranger Seismometer is a one-second natural period velocity transducer. A $1.45 \mathrm{Kg}$ mass is allowed +/- 1 $\mathrm{mm}$ of travel with an external resistance of $70 \%$ of critical.

The equipment manufacturer (Kinemetrics and their subsidiary Agbabian Associates) ivas present prior to the deployment to assist SRTC on setting the event recorder parameters and synchronize the recorder quartz clocks. Calibration specifications for the recorders and the sensors were provided by the manufacturer.

\section{Instrument Deployment and Recovery}

Instruments were deployed on the morning of April 7, and recovered the following day. The freo-field sensors were positioned on steel plates, each plate being approximately 1 ft square and $1 / 2$ in. thick, pushed approximately 1 in. into the soil. Once the sensors were positioned, level indicators were used to adjust the sensor footings to insure proper orientation. The vertical $(V)$ component is up, the longitudinal (L) component on the SSAs were oriented along the building east-west direction, and the L-component for the SSR is oriented along the building north-south direction. The transverse (T) component on all sensors measures a horizontal component orthogonal to the L-component.

\section{Description of Shot Data}

The ten minute unfiltered velocity records recovered from both SSR-1 recorders are shown in Figure 5. The vertical, radial, and transverse components are shown for the freefield (top of figure) and the - 40 level of K-Reactor (bottom of figure); signal trace amplitudes illustrated are in millivolts. Shot times are one minute, three minutes, five minutes, and 7 minutes into the record shown corresponding to New Ellenton, Snelling, Olar, and Lodge shots. The Walterboro shot was an hour later, outside the recording window. Ambient noise levels are clearly higher in the reactor as evidenced by higher amplitudes. First arrivals are clearly identified for Shots 1, 2, and 3 in the free-field recording, and Shots 2 and 3 can be identified in the Reactor records. The accelerometers in K-Reactor recorded a noise level of approximately $.4 \mathrm{gals}(4 \mathrm{E}-04 \mathrm{~g})$, below the threshold of accelerations. 
Surprisingly, the motions recorded from the second and third shot at K-Reactor were more energetic than the first (the New Ellenton shot being the largest and closest to $\mathrm{K}$ Reactor). Possible reasons for this are: (1) the New Ellenton shot was set below sediments into bedrock, and the transmissioti of energy into the sediments was reduced by the strong acoustic sediment/bedrock impedance; (2) significant energy from shots set within the sediments (Snelling, Olar, and Lodge) may have been trapped in the Coastal Plain Sediments; (3) preliminary interpretation of the refraction data (Madabhushi et al., 1991) suggests the Snelling shot was set directly above the Dumbarton Triassic Basin, and that this Basin's acoustic properties may have trapped significant energy, which could be directed to $\mathrm{K}$ Reactor (which is aiso located above the Dumbarton Basin). Sediment propagation is also suggested from the $0.3 \mathrm{~km} / \mathrm{sec}$ group velocities seen in the 2 nd shot coda.

The peak vertical amplitude for the Snelling shot was reduced on the foundation recording by $30 \%$ over that recorded in the free-field. Horizontal component peak motions were reduced further. A more complete comparison of the motions is described in the discussion of the frequency domain.

Ir order to directly apply an empirical transfer function to e thquake design, it is desirable to have the presence of st ong (high-strain) SH-waves (horizontally polarized sh ar-waves). These notions are low-strain, and there were no obvious S-waves apparent from the records, however, pailticle motion studies could assist in the understanding of wave types and origin on signals recorded in $\mathrm{K}$-Reactor. $\mathrm{A}$ particle motion analysis will be a subject of a later report.

\section{$\mathrm{Sp}:$ ctral Ratio Analysis}

In oil der to make frequency dependent determination of the fouri lation effect, a complex representation of a time series is usi $d$. One can then define the complex Fourier spectra of a cor ponent of the foundation time series as $Y(f)$ and the free-lield time series as $X(f)$. As a true transfer function is comple s (contains signal amplitude and phase), we estimate the re amplitude ratio that does not contain phase:

$$
H(f)=\sqrt{\frac{Y^{\prime}(f) Y(f)}{X^{\prime}(f) X(f)}}
$$

where' denotes complex conjugation. To reduce the effects of noise present in the signals, pre-event power spectral noise was computed for otherwise identical component, smoothing operator, and window length, then these estimates were subtracted from power spectral signal windows.

A computer code for signal analysis called SPECR2 was developed for this application: (1) horizontal components were rotated to radial and transverse directions for each of the three shots processed; (2) data and noise samples were windowed, signal means removed and cosine taper applied at window ends to reduce truncation effects in the spectra; (3) a Cooley-Tukey Fast Fourier Transform algorithm was used to process pro-event noise and signal windows separately (noise was assumed to be stationary); (4) a triangular smoothing operator was applied to spectral amplitudes; (5) pre-event power spectral noise recorded separately at foundation and freo-field were subtracted from power spectral signals prior to ratio estimates; (6) spectral amplitude ratios between foundation and free-field were computed for the second and third shots; ( 7 ) identification was made of frequency bands where signal-to-noise ratios $(\mathrm{S} / \mathrm{N})$ were 2.0 or greater for both numerator and denominator.

\section{Snelling Shot (Shot \#2)}

Figure 6a, b, c, and d are 512, 1024, 2048, and 4096 point samples (corresponding to $5.1,10.2,20.5$, and 41.0 seconds) of the transverse component of the second shot. The figure shows windowed trace amplitude in meters/second, and smoothed Fourier amplitude spectra for the windowed segment (solid line) and a similar period of pre-event noise (dashed line) for records taken on the foundation and in the free-field. Note the cleaner free-field signal, exemplified by greater $S / N$ except at frequencies $9 \mathrm{~Hz}, 18 \mathrm{~Hz}$, and $23 \mathrm{~Hz}$. The foundation spectra exhibits good S/N from about 1 to 15 $\mathrm{Hz}$ except for a spike at about $9 \mathrm{~Hz}$.

Figure 6 also illustrates the common log of Fourier amplitude spectral ratios (with power spectral noise subtracted) plotted against linear frequency. The high and low extremes are a result of poor $\mathrm{S} / \mathrm{N}$ but the trend of the ratio clearly indicates a gradual reduction of foundation amplitudes compared to free-field with increasing frequency. Comparison of spectra and spectral ratios for increasing window size shows an insensitivity to window length. This suggests that although the signals may be a combination of compressional, converted, and higher mode surface waves, a similar 
result might be expected for pure vertical incident SHwave.

Foundation and free-field vertical, radial, and transverse component spectral and ratios for Shot 2 are shown in Figures 7,8 and 9 respectively. Frequency bands where either foundation or freo-field spectra S/N was less than 2.0 are shown as shaded areas. Horizontal component foundation amplifications of an approximate factor of 2 are observed at about $1 \mathrm{~Hz}$ and $3 \mathrm{~Hz}$ for the transverse and radial components respectively. For frequencies greater than 2.5 to $5 \mathrm{~Hz}$, horizontal component ratios show substantial and consistent reductions of foundation amplitudes (approximately 50\%),

The seismic frequencies associated with reductions in foundation motions are consistent with the foundation dimensions and soil properties. Taking a shear-wave velocity of $1,500 \mathrm{f} / \mathrm{sec}$ (a value measured in shallow soils adjacent to K-Reactor) and building dimensions of $500 \mathrm{ft} \times 300 \mathrm{ft}$, we would expect horizontal component S-wave signal averaging to occur in the foundation for frequencies greater than 3 $\mathrm{Hz}$ to $5 \mathrm{~Hz}$.

Second shot vertical component ratios show ar: apparent 2-fold foundation amplification at about $5 \mathrm{~Hz}$ and $7 \mathrm{~Hz}$, and approximately $50 \%$ reduction from 10 to $14 \mathrm{~Hz}$. Near consistent foundation and free-field motiuns are evident from 15 to $17 \mathrm{~Hz}$.

\section{Olar Shot (Shot \#3)}

Figures 10,11 , and 12 are the vertical, radial, and transverse components of the free-field and foundation motions, spectra, and spectral ratios. Although only narrow frequency bands have useful $\mathrm{S} / \mathrm{N}$ for ratio estimation, it is worthwhile to check the consistency of Shot 2 and 3 foundation/freefield ratios. Different foundation response might be expected because of the approximate 90 degree change in azimuth between Shots 2 and 3 . Vertical component spectra ratio shapes are consistent with Shot 2, except that the amplifications at $5 \mathrm{~Hz}$ and $7 \mathrm{~Hz}$ are diminished. Comparison of radial components of Shots 2 and 3 also are in agreement except at $2 \mathrm{~Hz}$, where there is an approximate factor of 4 difference in the ratios. The transverse component ratio of Shot 3 exhibits similar amplification and reduction character as Shot 2, but appears more variable (ratio differences between s'iots of about a factor of 2).

\section{New Ellenton Shot (Shot \#1)}

Figure 13 shows vertical, radial, and transverse component motions and spectra of Shot 1. A clear first arrival is apparent on the free-field vertical component, but horizontal components do not exhibit later arrivals nor spectral energy above background noise. These observations would be consistent with the deeper New Ellenton source, not exciting fundamental and higher-mode coastal-plain sediment surface waves. Poor S/Non both foundation and free-field data precludes a spectral ratio estimate for Shot 1.

\section{Conclusions and Discussions}

Despite high seismic noise levels present in K-Reactor and nearby environment, wide band (1-15 Hz and greater) signals were recorded on the foundation and adjacent to the Reactor for purposes of understanding the reaction of the deeply embedded foundation to incident seismic energy.

For Shot 2, substantial reductions are observed in reactor horizontal components for frequencies greater than about 3 to $5 \mathrm{~Hz}$. These reductions are consistent with anticipated effects of an embedded rigid foundation of K-Reactor dimensions. Vertical component spectral ratios show significant amplification at $5 \mathrm{~Hz}$ and $7 \mathrm{~Hz}$, but show reductions or no amplifications at other frequencies.

Signals associated with Shots 1 and 3 recorded in K-Reactor, had only limited bandwidth atove background noise. Where there were adequate $S / N$, spectra and spectral ratios associated with Shot 3 were remarkably consistent with Shot 2.

The real-valued and frequency dependent spectral amplitude ratios, developed from these measurements, may be useful for verifying analytical K-Reactor foundation response. A task is now underway to verify foundation response by using the response spectral ratios as a check on the analytical foundation response to low-strain and incoherent earthquake motions. Consideration for source-to-Reactor azimuth, angle of incidence, and partition of compressional and shear energy may be important to reactor response and should be incorporated in the analysis. Additional analysis to identify and isolate specific wave-tupes may also be worthwhile. 


\section{References}

Campbell, K.W., 1989. "Empirical Prediction of NearSource Ground Motion For the Diablo Canyon Power Plant Site", San Luis Obispo County, Califomia, Department of the Interior, United States Geological Survey Open-File Report 89-484, 115p.

Cooley, J.W. and J.W. Tukey, 1965. An algorithm for the machine calculation of complex Fourier series, Math. Comput., Vol. 19, pp. 297-301
Madabhushi, S., P. Talwani, H. Befn', J. Luetgert, W. Mooney, and E. Criley, 1991. "Shallow Crustal Structure Beneath the South Carolina Coastal Plain", EOS, Trans actions, American Geophysical Union, Vol. 72, No. 44, October 29, 1991, p. 428.

South Carolina Electric and Gas, 1983. Seismic Confirmatory Program, Virgil C. Summer Nuclear Station Unit 1, OL No. NPF-12. 

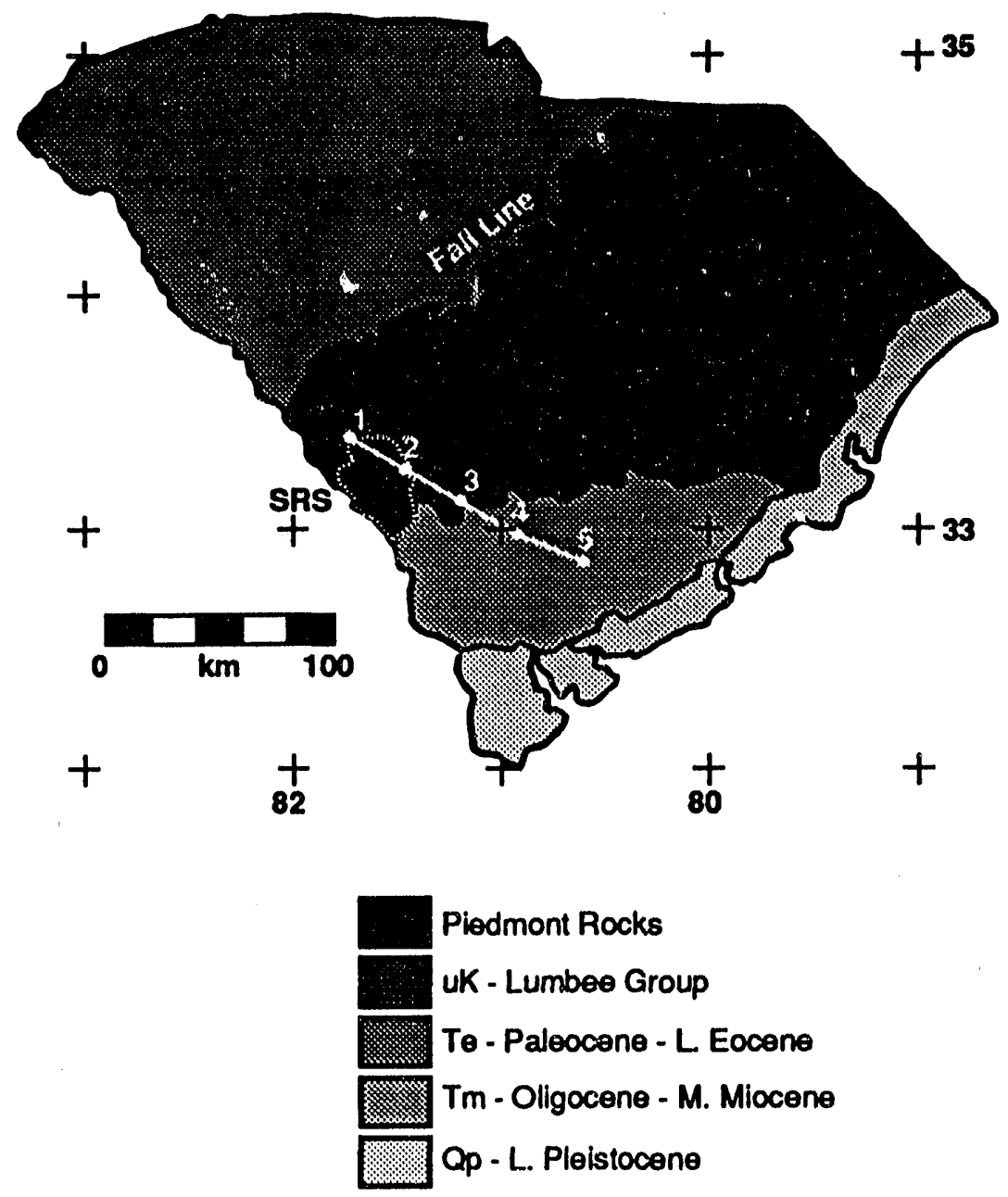

(Legend modified from

Goologic Map of U.S., 1974)

M92C046.01

Figure 1

Modified geologic map of South Carolina showing the location of April 7, 1991 seismic refraction/wide angle reflection experiment. The five shot locations numbers 1-5 correspond to localities New Ellenton, Snelling, Olar, Lodge, and Walterboro. The dense network of recorders is shown by the interconnecting white line. 


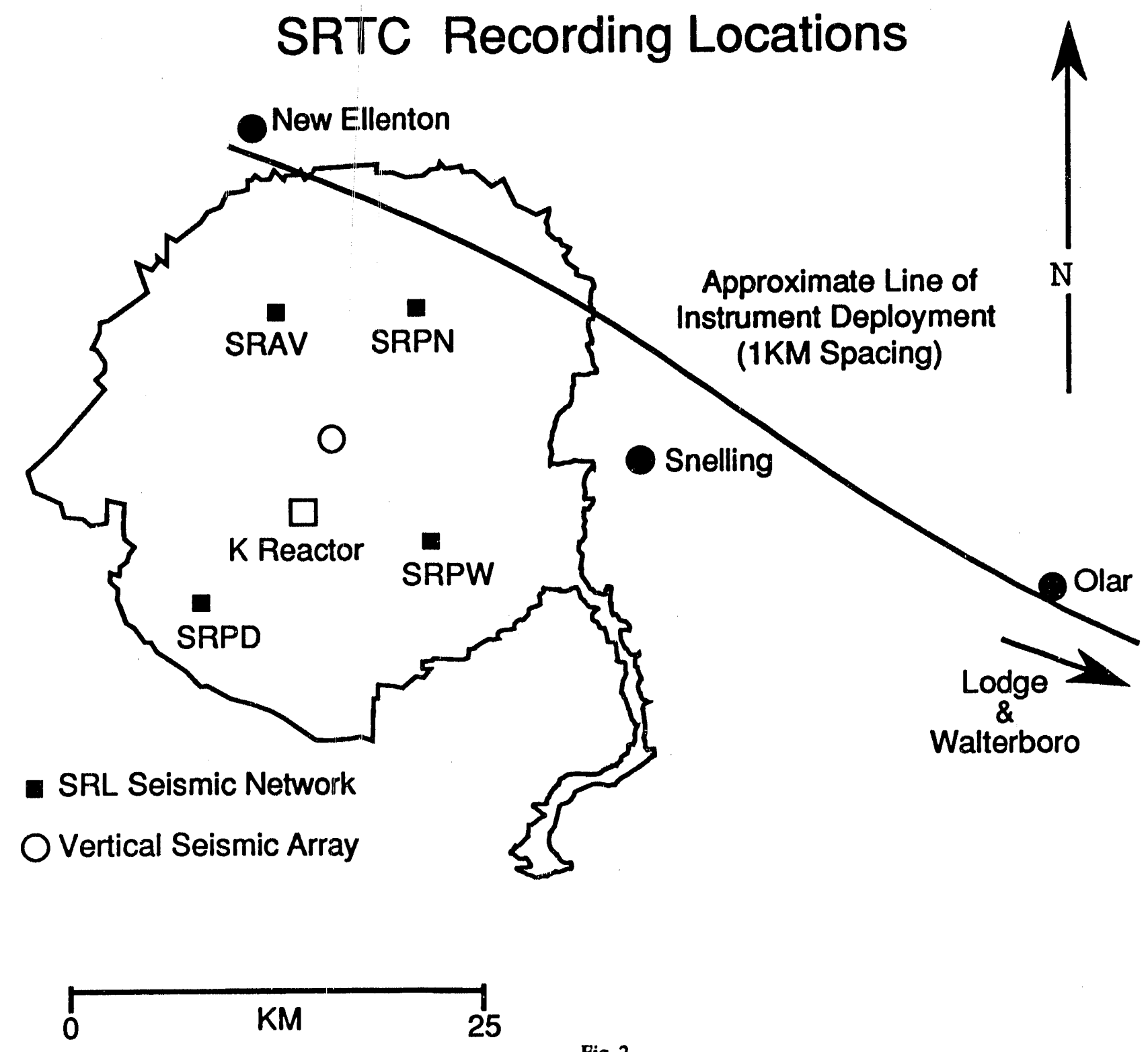

Fig. 2

M92C046.02

Figure 2 Iflustration of instrument deployment, locations of SRTC permanent network, and K-Reactor. Approximate shot locations shown for New Ellenton, Snelling, and Olar. 


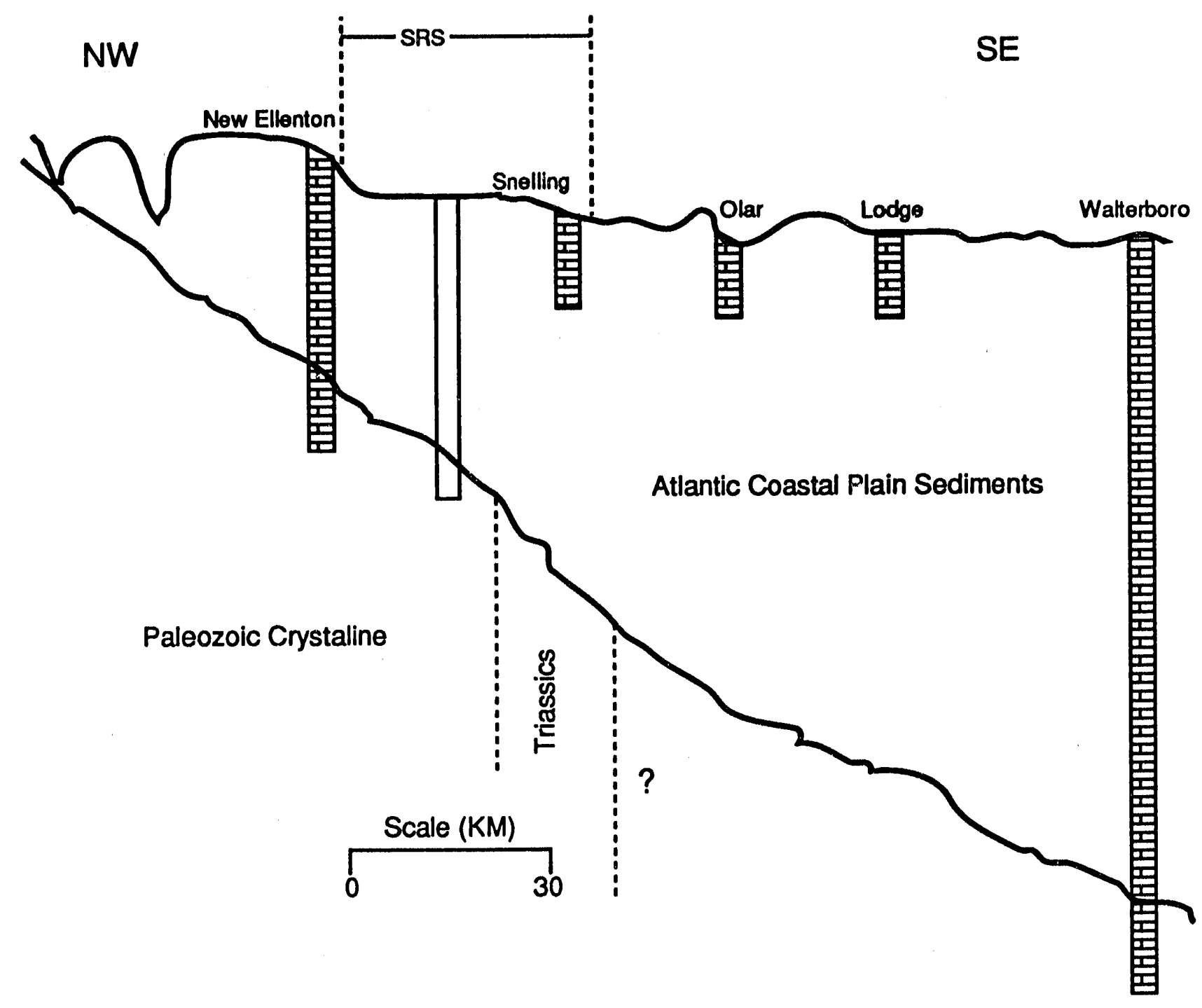

M92C046.03

Figure 3 Cross-section (vertically exaggerated) showing extent of charges placed in bedrock and sediments. 

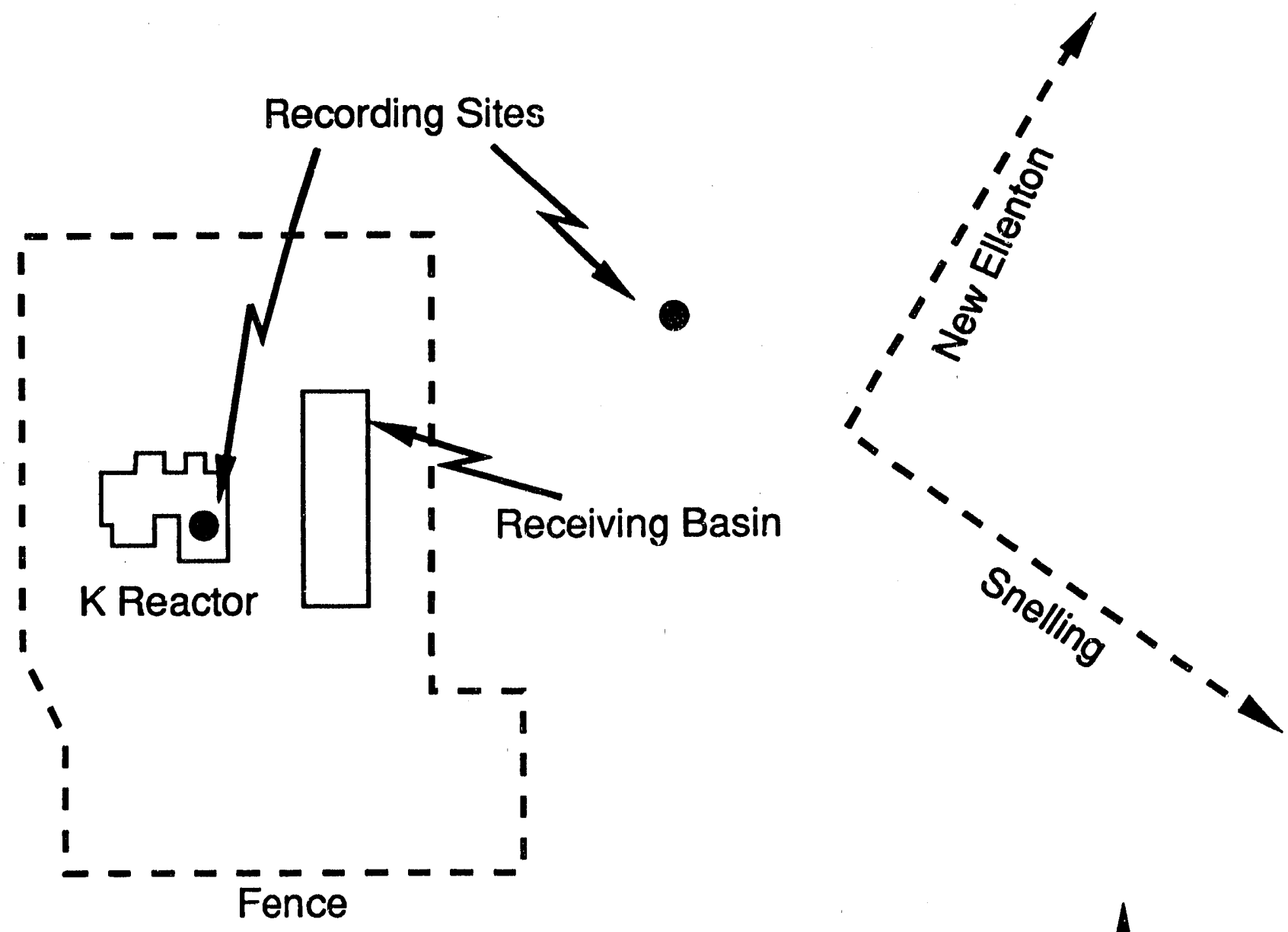

$1000 \mathrm{ft}$.

M92C046.04

Figure 4 nents at both locations aligned to site coordinate system. New Ellenton and Snelling shot directions are shown by arrows. 


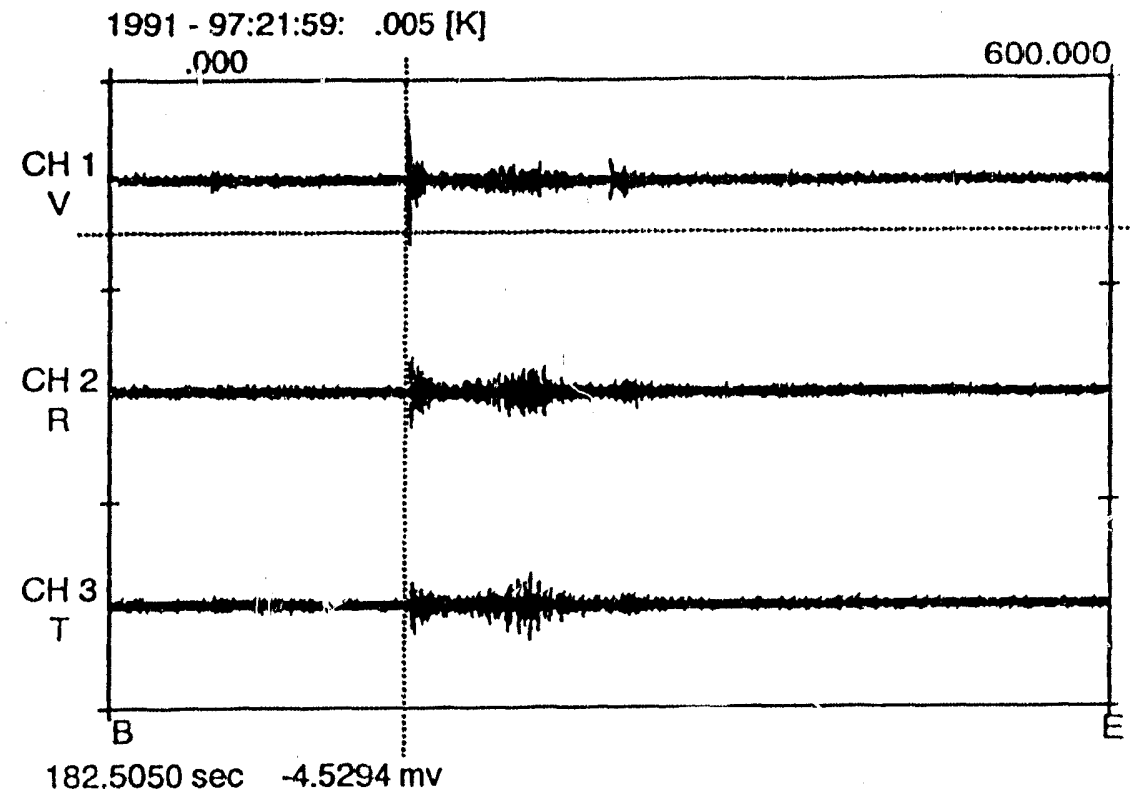

Foundation

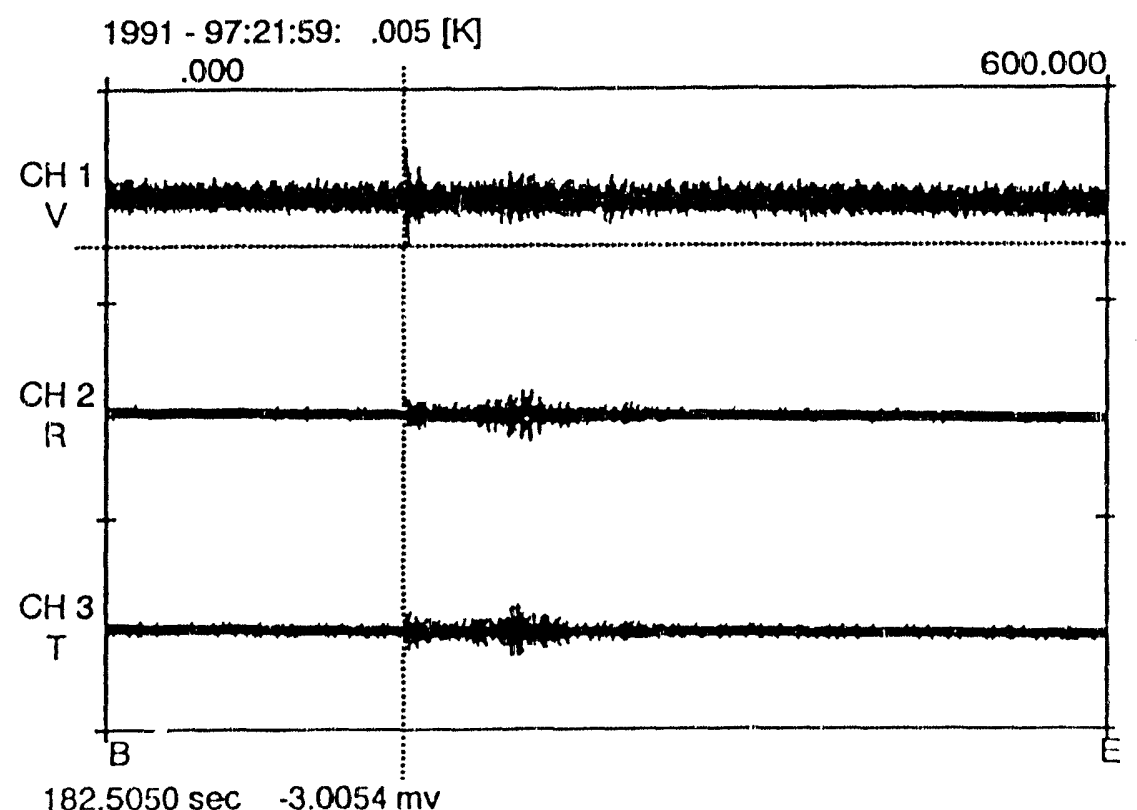

M92.CO46.C15

Figure 5 Vertical, site north-south, and site east-west components for continuous 10-minute recording during the experiment for free-field site near KRP 1 and -40 Level of K-Reactor. Amplitudes aie in millivolts and sensitivities are approximately 150 volts/meter/second. 


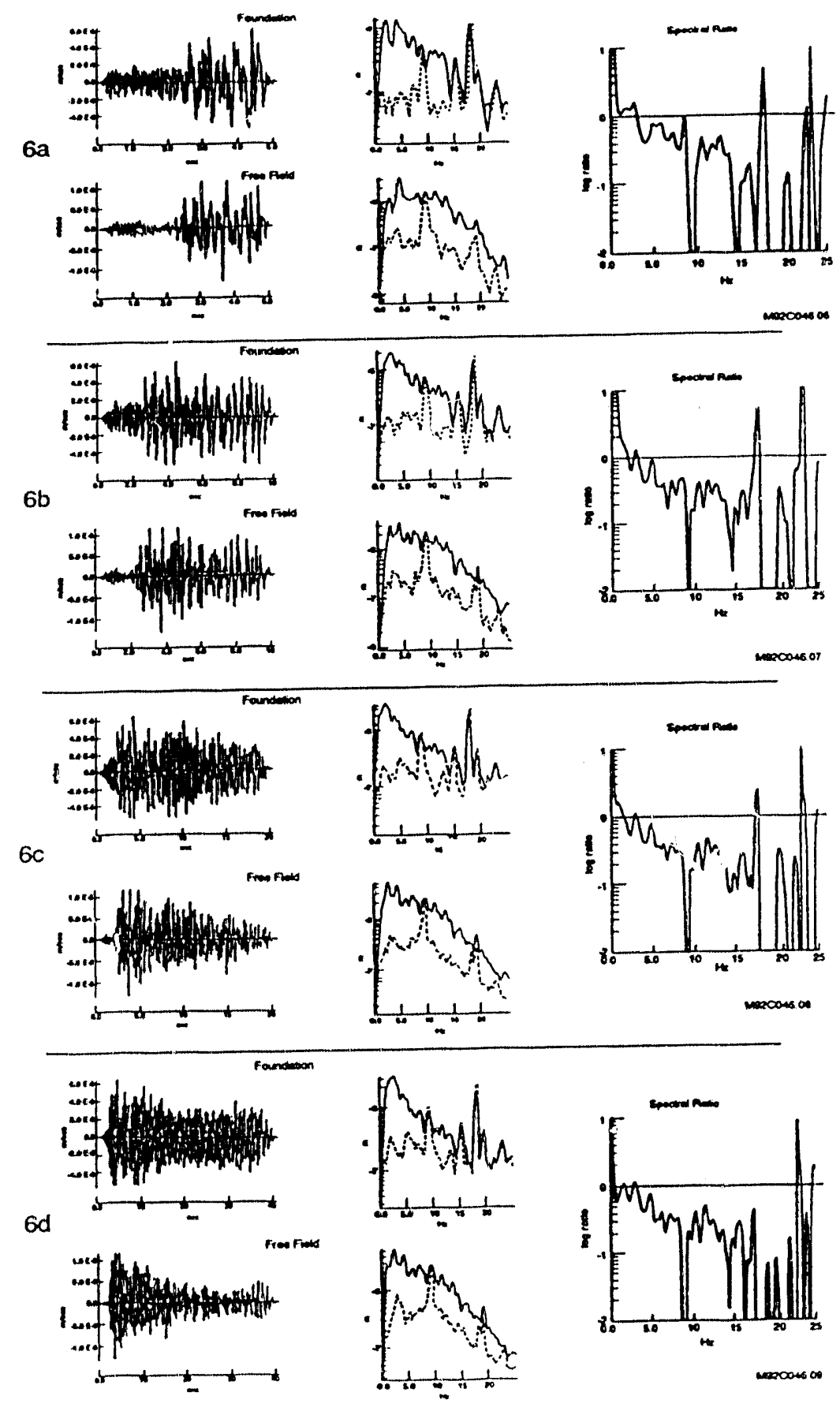

Figure 6

Snelling shot (shot \#2) transverse component reactor and free-field traces, amplitude spectra, pre-event noise spectra, and spectral amplitude ratio. All windows are $10 \%$ cosine tapered, and illustrate insensitive nature of spectral ratio to window lengths: (a) $5.1-\mathrm{sec}$ window; (b) 10.2- $\mathrm{sec}$ window; (c) 20.5- $\mathrm{sec}$ window; and (d) 41.0-sec window. 


\section{Foundation}

(a)
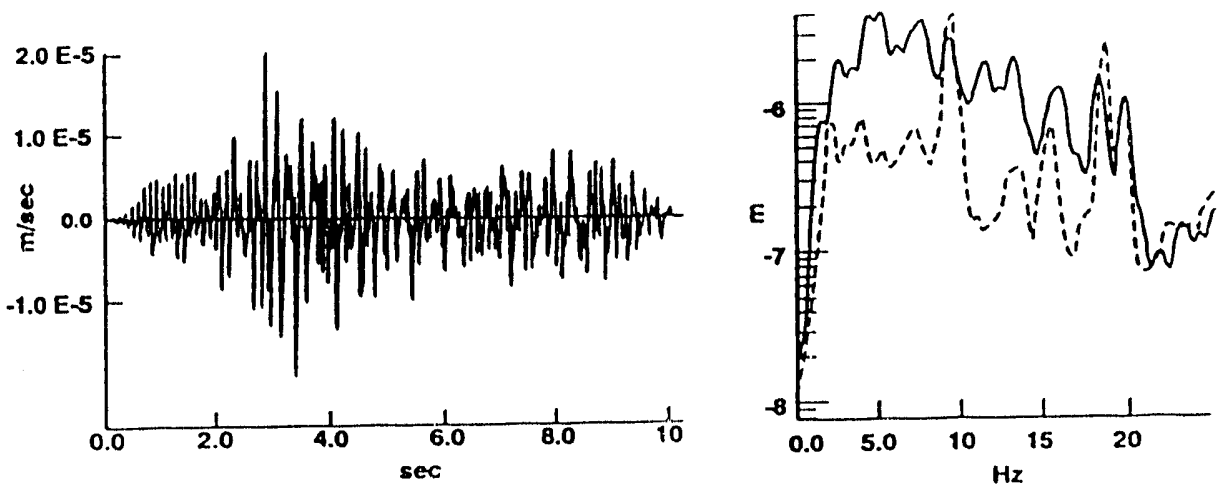

Free Field

(b)
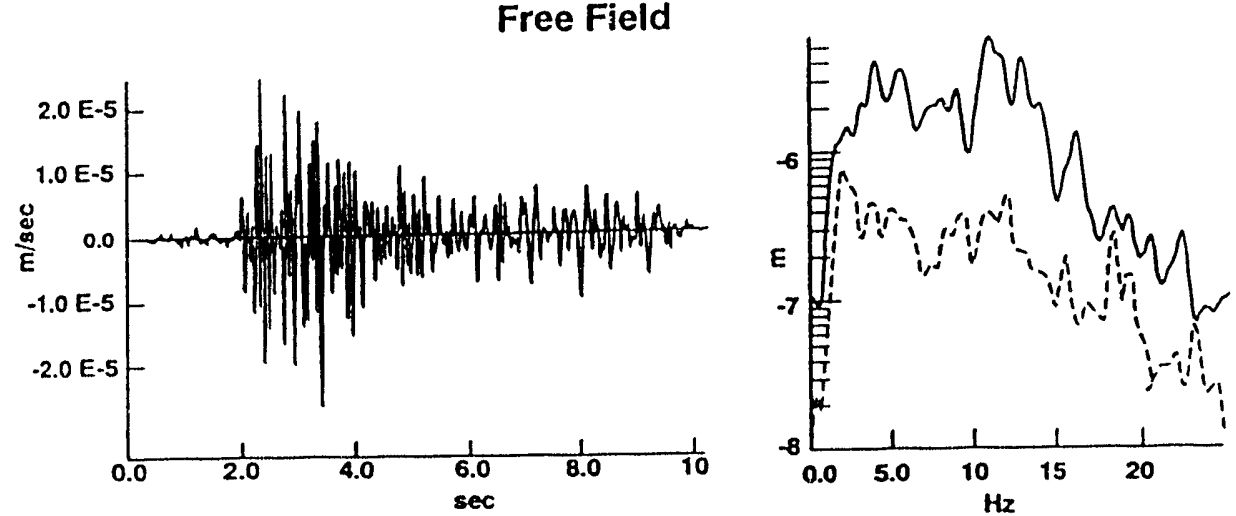

Spectral Ratio

(c)

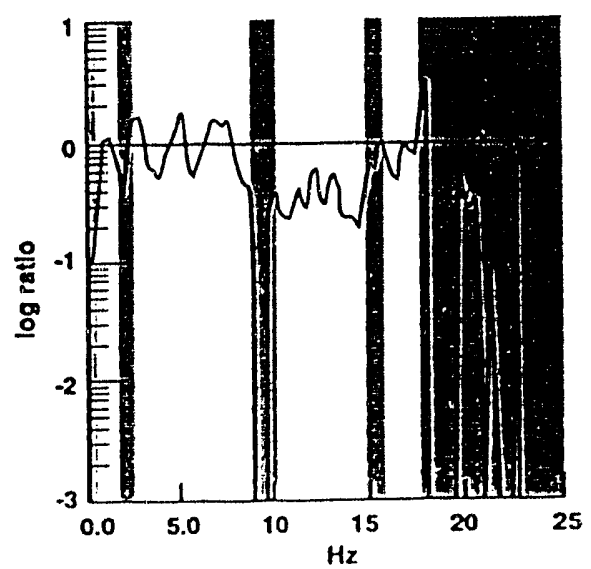

M92C046.10

Figure 7

Shot \#2 vertical component: (a) foundation motions, corresponding spectra (solid line), and pre-event noise (dashed linca); (b) free-field motions, corresponding spectra (solid line), and pre-event noise (dashed line); (c) comnion logarithm of spectral amplitude ratios vs frequency (shaded for frequency bands where $S / N<2.0$ for either recording). 
Foundation

(a)

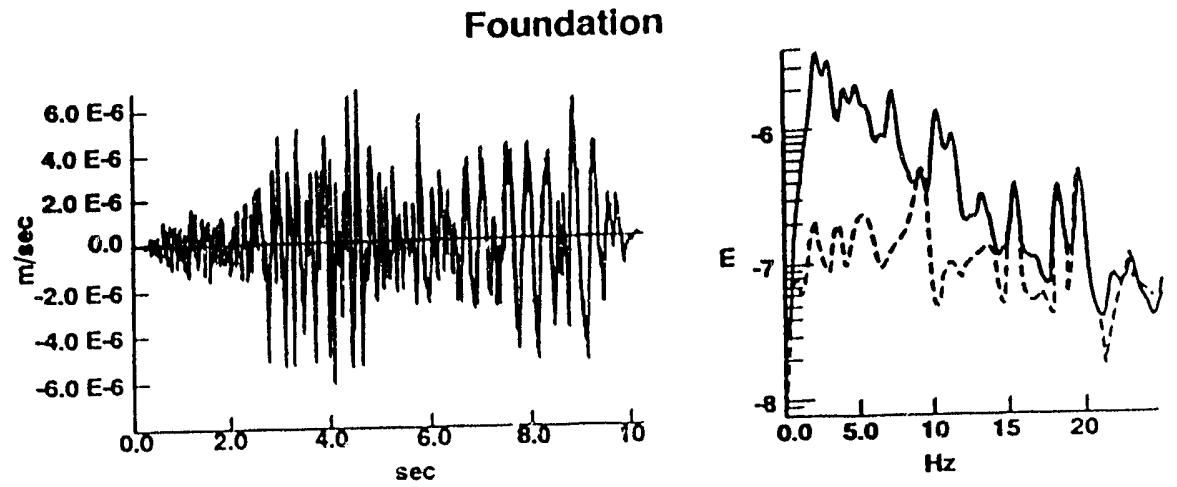

Free Field

(b)
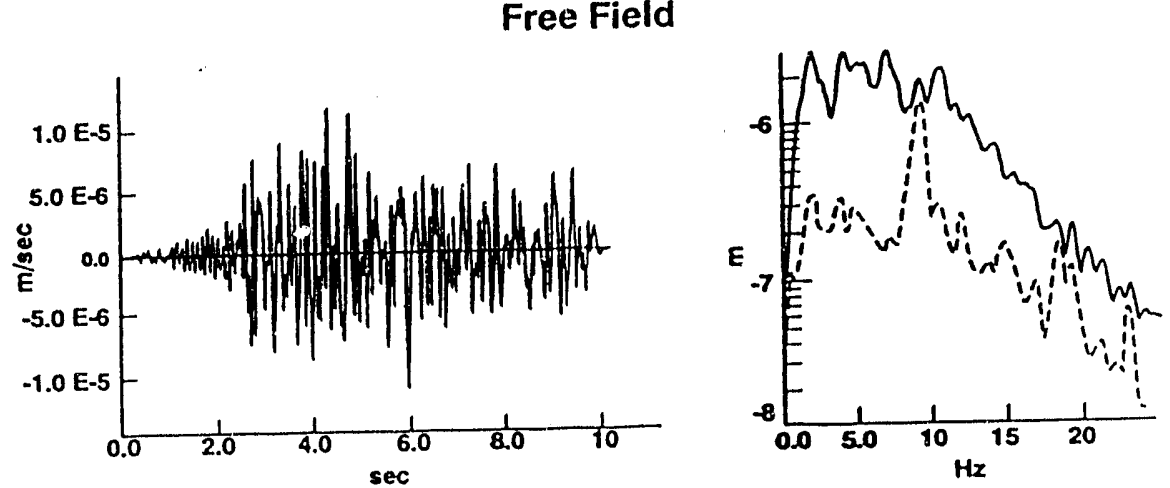

(c)

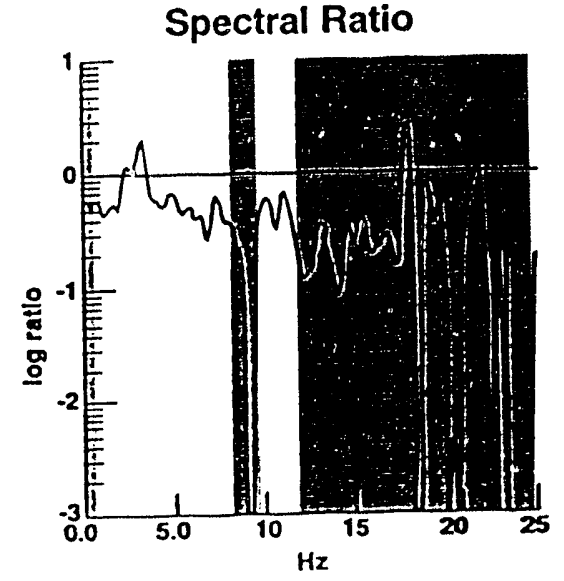

M92C046.11

Figure 8

Shot \#2 radial component; (a) foundation motions, corresponding spectra (solid line), and pre-event noise (dashed line); (b) free-field motions, corresponding spectra (solid line), and pre-event noise (dashed line); (c) comimon logarithm of spectral amplitude ratios vs frequency (shaded for frequency bands where $\mathrm{S} / \mathrm{N}<2.0$ for either recording). 


\section{Foundation}

(a)

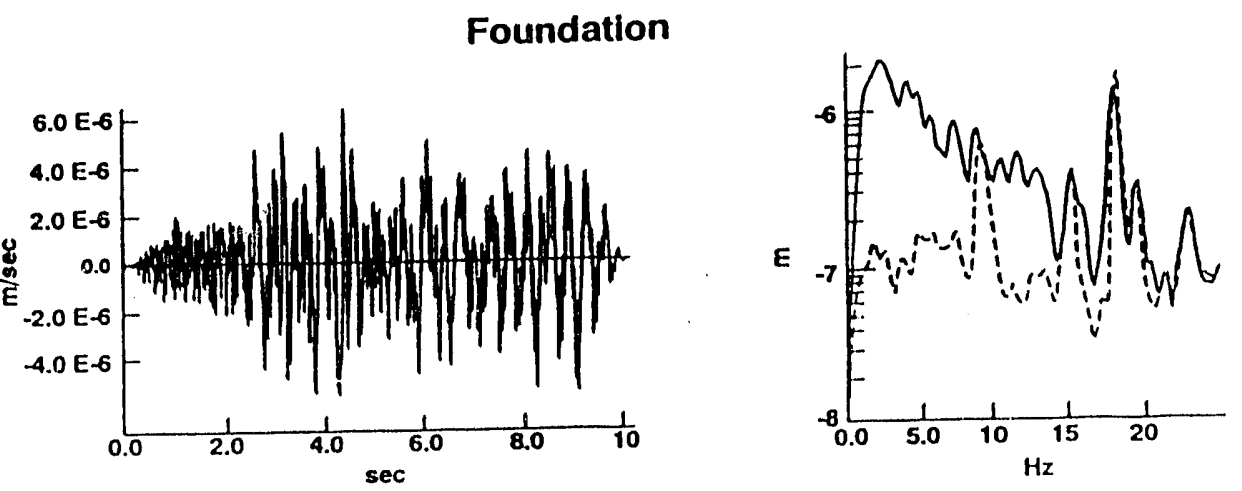

Free Field

(b)
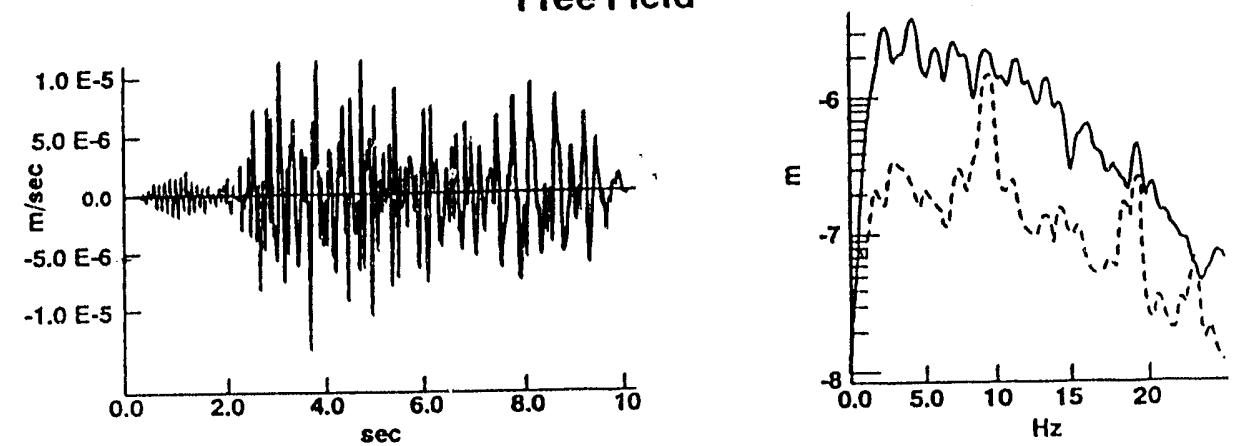

\section{Spectral Ratio}

(c)

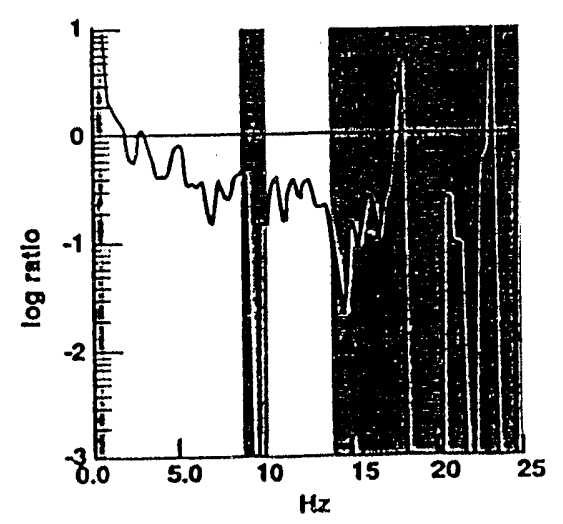

M92C046.12

Figure 9

Shot \#2 transverse component: (a) foundation motions, corresponding spectra (solid line), and pre-event noise (dashed line); (b) free-field motions, corresponding spectra (solid line), and pre-event noise (dashed line); (c) common logarithm of spectral amplitude ratios vs frequency (shaded for frequency bands where $S / N<2.0$ for either recording). 
(a)

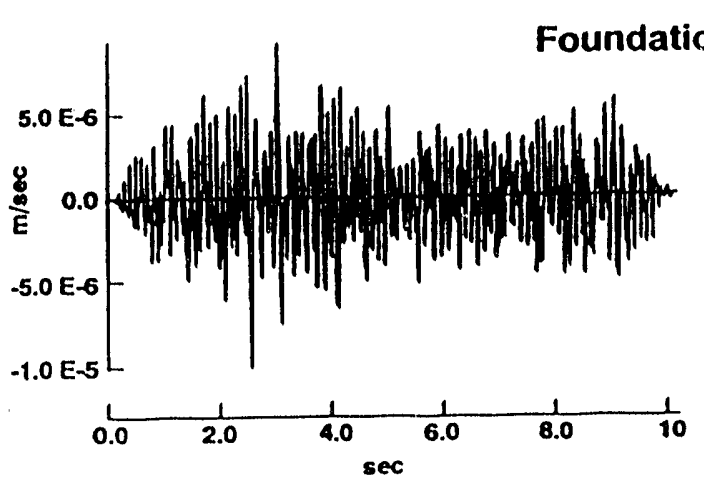

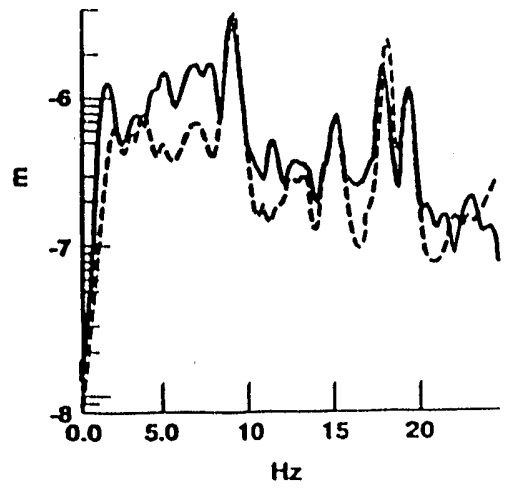

Free Field

(b)

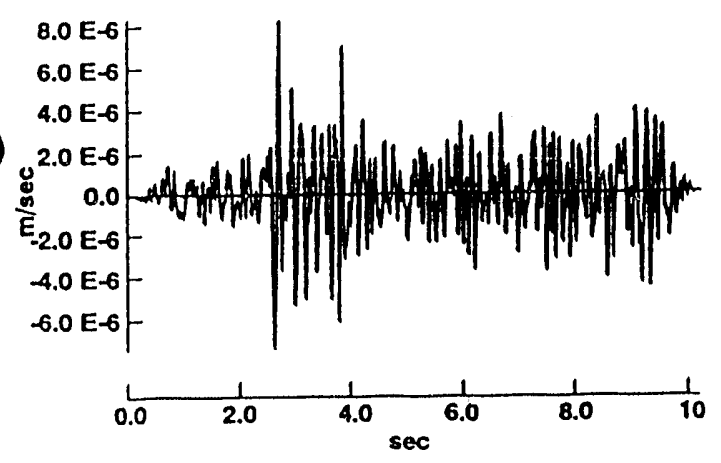

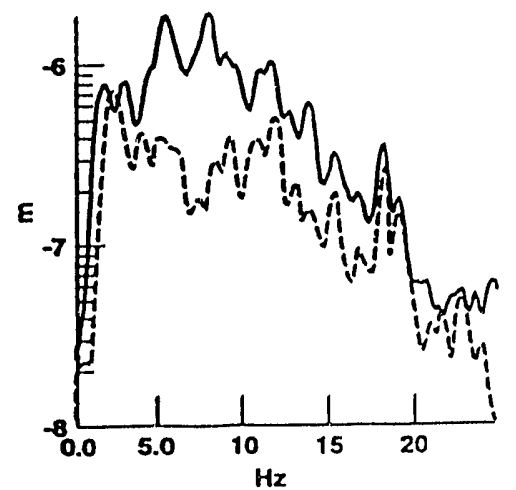

Spectral Ratio

(c)

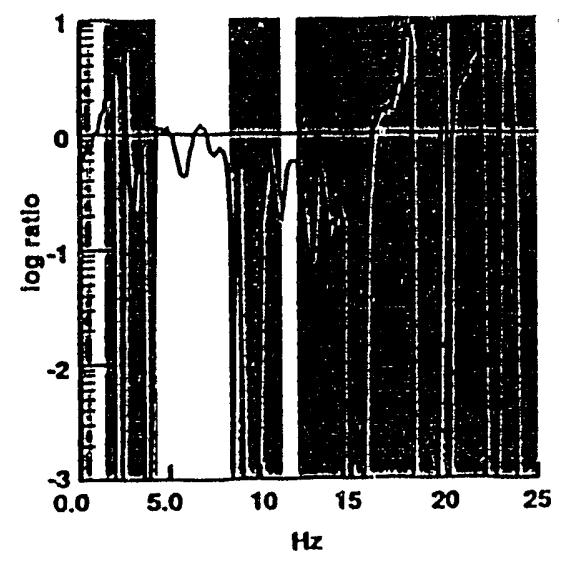

M92C046.13

Figure 10

Shot \#3 vertical component: (a) foundation motions, corresponding spectra (solid line), and pre-event noise (dashed line); (b) free-field motions, corresponding spectra (solid line), and pre-event noise (dashed line); (c) common logarithm of spectral amplitude ratios us frequency (shaded for frequency bands where $\mathrm{S} / \mathrm{N}<2.0$ for either recording). 
Foundation

(a)

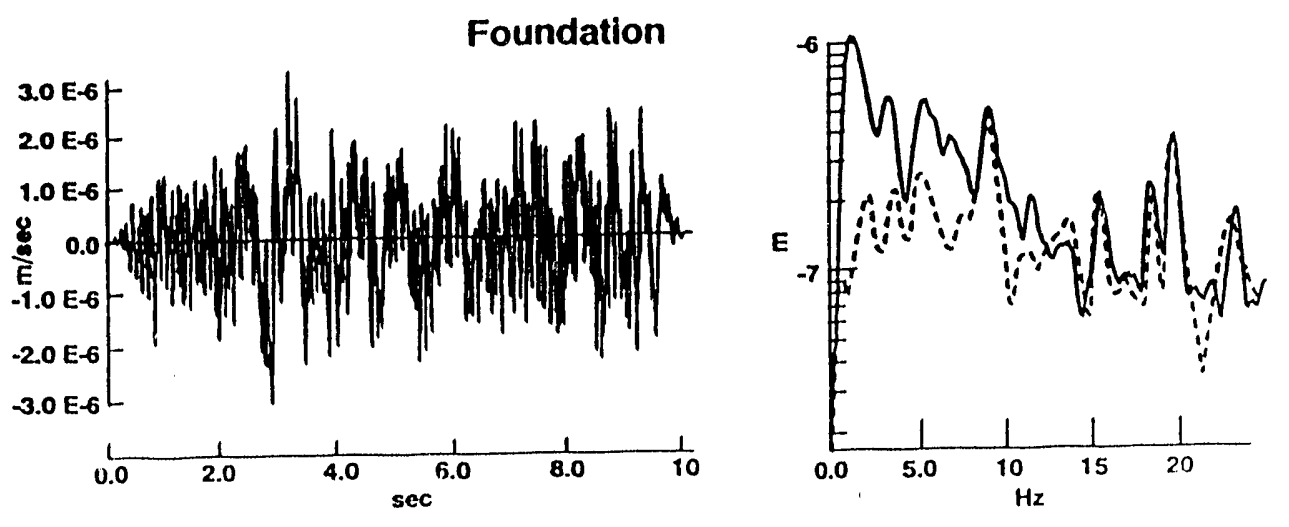

(b)
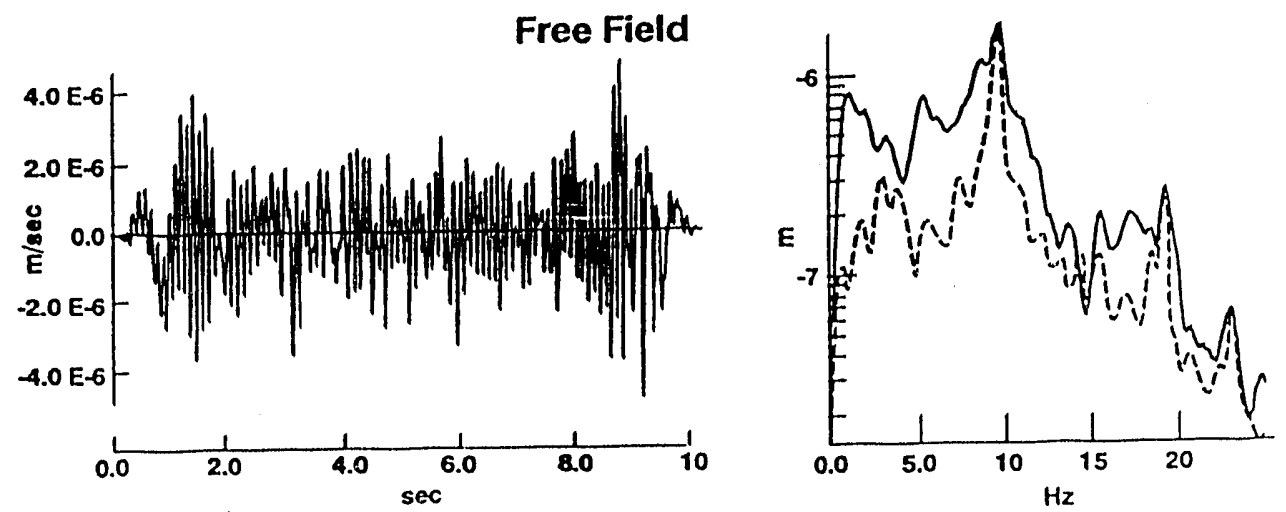

Spectral Ratio

(c)

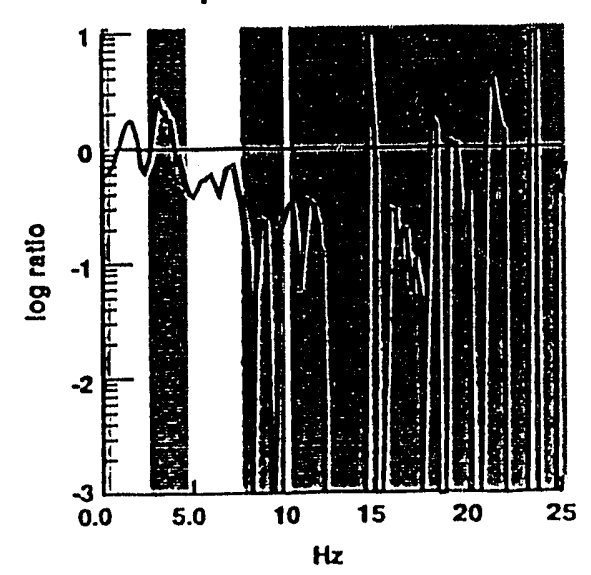

M92C046.14

Figure 11

Shot \#3 radial component: (a) foundation motions, corresponding spectra (solid line), and pre-event noise (dashed line); (b) free-field motions, corresponding spectra (solid line), and pre-event noise (dashed line); (c) common logarithm of spectral amplitude ratios vs frequency (shaded for frequency bands where $\mathrm{S} / \mathrm{N}<\mathbf{2 . 0}$ for either recording). 


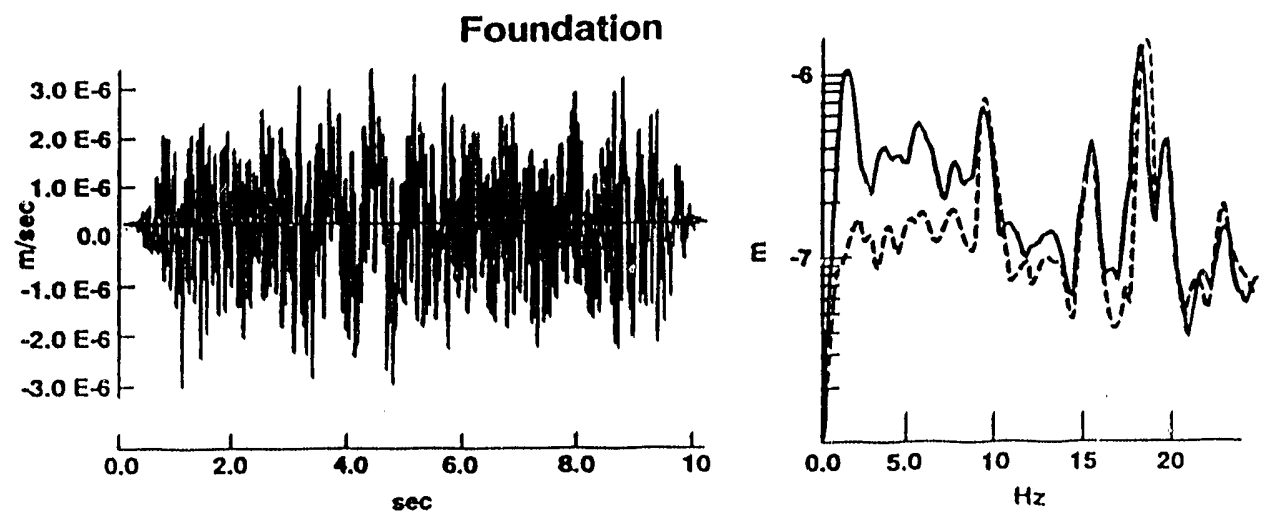

(b)
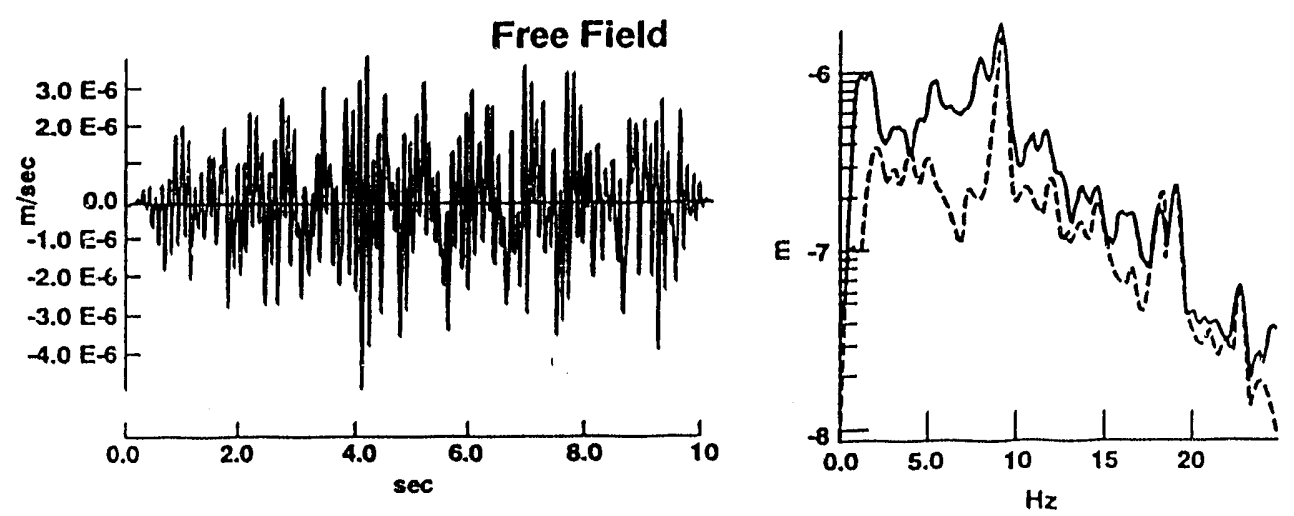

Spectral Ratio

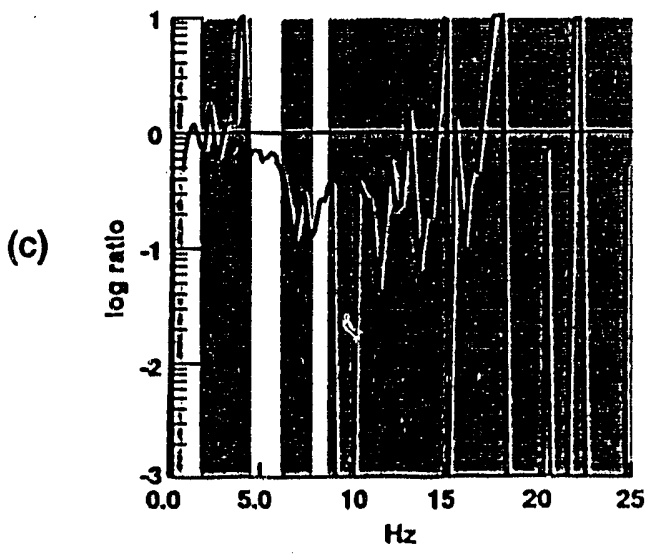

M92C046.15

Figure 12

Shot \#3 transverse component: (a) foundation motions, corresponding spectra (solid line), and pre-event noise (dashed line); (b) free-field motions, corresponding spectra (solid line), and pre-event noise (dashed line); (c) common logarithm of spectral amplitude ratios vs frequency (shaded for frequency bands where $S / N<2.0$ for either recording). 
(a)
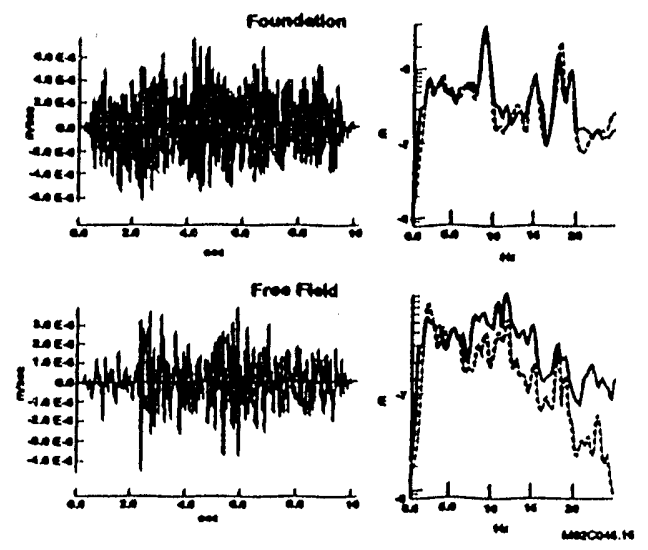

(b)
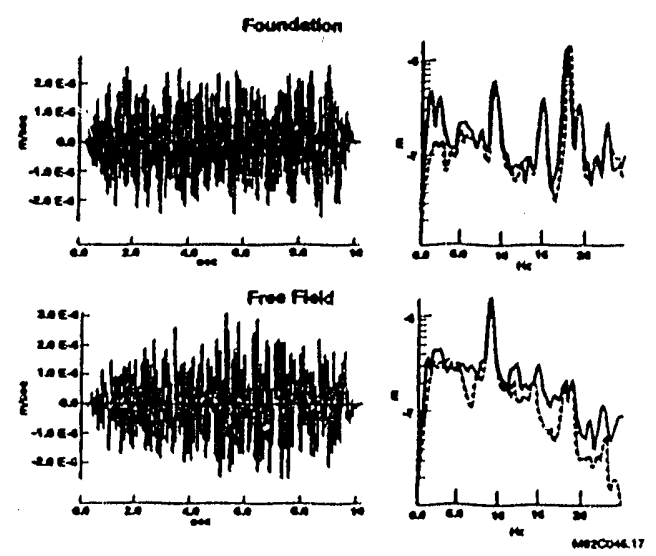

(c)
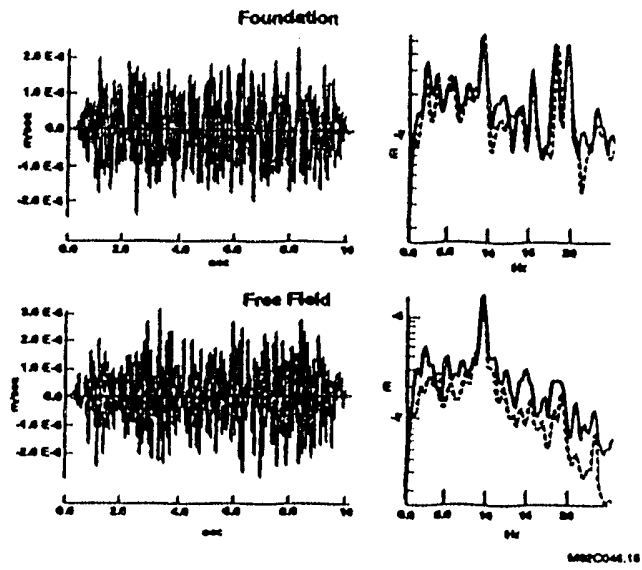

- Figure 13

Shot \#1 foundation motions, corresponding spectra (solid line), and pre-event noise (dashed line) for: (a) vertical component; (b) radial component; (c) transverse component. 
Table 1. Source Location Data

Site

New Ellenton

Snelling

Olar

Lodge

Walterboro
Shot Depth

(ft)

700

100

120

100

2300

Yield
(lb)

2000

900

1500

900

62

2000

93 

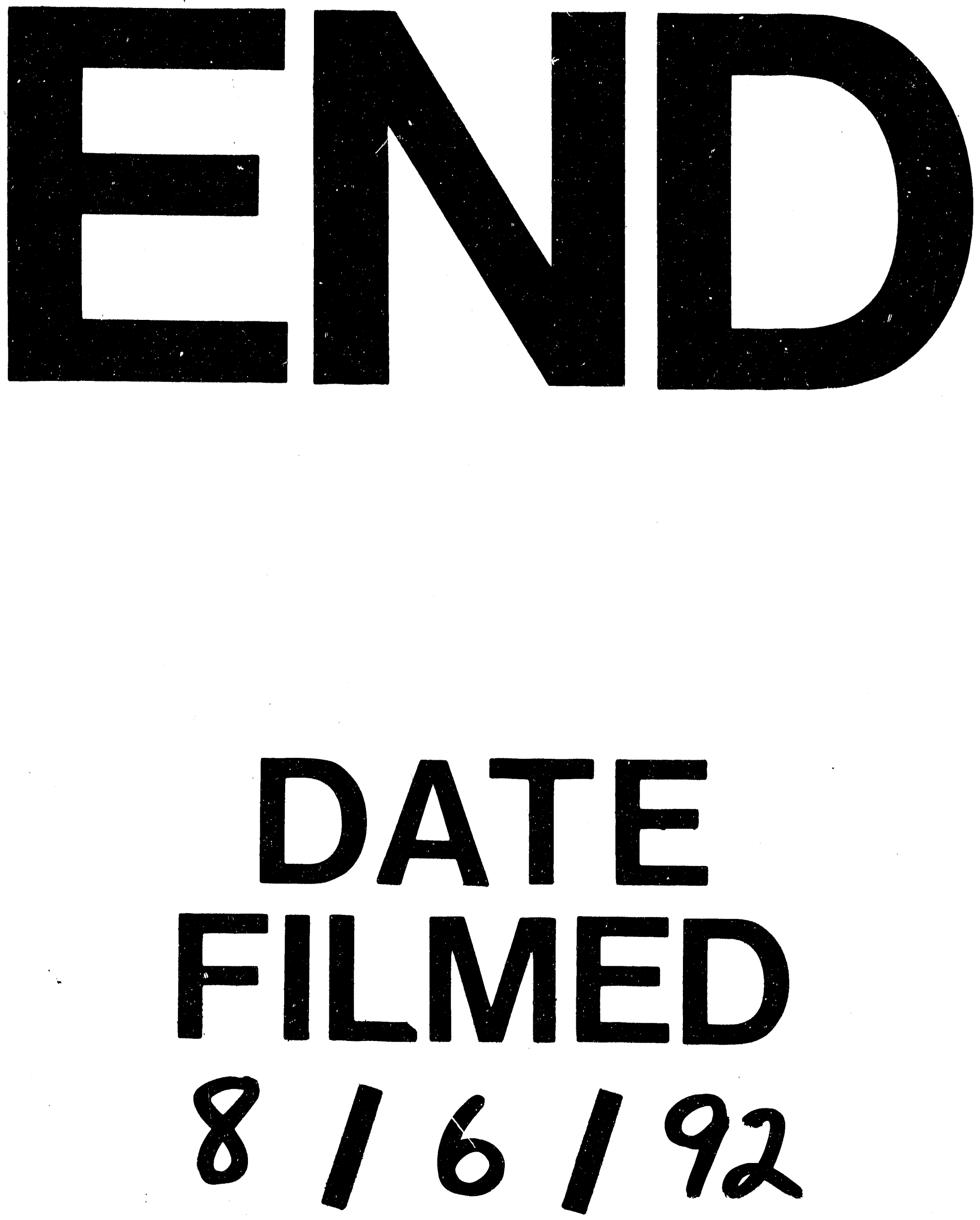
